\title{
Social aspects of uncertainty
}

\section{Sztabiński, Franciszek, Damański, Henryk and Sztabiński, Paweł (eds.) (2018) New Uncertainties and Anxieties in Eurupe. Berlin: Peter Lang. 285 pages.}

This book is part of a series of volumes that aim to give insight into selected findings from the European Social Survey. In frame of the ESS research every two years, faceto-face interviews are conducted with newly selected, cross-sectional samples and a huge emphasis is put on the dissemination of the results. A great merit of the book is that it includes all countries participating in the research between 2002 and 2014. As it is an edited volume it contains several different topics with special emphasis on the consequences of sweeping changes in social relations with respect to uncertainty that is related to globalization of labour markets, intensified competition and the accelerated spread of networks and new technologies.

The first part of the book consists of studies concerning migration, xenophobia, and ethnic discrimination.

Authors Jaak Billiet, Bart Meuleman and Eldad Davidov study the relation between ethnic threat and economic insecurity in times of economic crisis. They distinguish five study designs that are used to analyse the topic and offer a detailed overview of them. The chapter not only summarizes results of recent studies based on the given design but also presents figures and tables to enable readers to make an assessment of strengths and weaknesses of each design. Their analysis is based on Group Conflict Theory: according to this perspective, negative outgroup sentiments are seen as defensive reactions to perceived intergroup competition for scarce goods. Their findings provide clear evidence for the existence of longitudinal effects of economic conditions on economic threat perceptions: growing unemployment as well as decreasing rates of economic growth strengthen feelings of economic threat.

The second chapter focuses on Poland and Germany in a comparative perspective to explain what drives attitudes towards migrants and identification with populist parties. Peter Schmidt, Lucyna Darowska and Daniel Georg test 21 hypotheses and run three structural equation models separately for Poland as well as Eastern and Western Germany in order to find out whether deprivation, values or racism are the driving factors. A main finding of the chapter is that group related deprivation is strongly connected with economic threat in all three regions. However, the effect is the strongest in Eastern Germany and the weakest in Poland. The grouprelated deprivation is associated with cultural threat, which has the strongest effect of all measured factors on the rejection of migration. Biological racism has little indirect effect on migration, whereas values have a strong effect. Education plays a decisive 
role in Germany and Poland in relation to universalism, having negative mediatory effects on economic threat, fraternal deprivation and cultural threat.

In order to detect to what extent attitudes to migrants depend on economic and cultural threats, the chapter written by Zbigniew Karpiński and Kinga Wysieńska-Di Carlo analyse attitudes towards immigration in Europe. The authors do not formulate any new hypotheses, instead they test predictions stemming from existing theories regarding the sources of attitudes towards immigrants and immigration and aim to detect the attitudinal effects of changing contexts and macro-level/structural characteristics in a comparative perspective. Firstly, they present the theory of selfinterest and economic threat: as people compete for scarce resources, they exhibit negative attitudes towards any person or group that is perceived as threatening their status or position. Secondly, they mention values and symbolic threat as a set of explanations claiming that people's attitudes are also shaped by their values and social identities. People hold on to certain ideals, which they internalized early in life or during their education, and which foster support for or rejection of certain ideals of equality and diversity. These values, according to this viewpoint, are driving attitudes, independently of individual or group economic interests. The theory of ethnic competition and related contextual variables explains that both economic and symbolic threats are assumed to respond to the same conditions. Therefore, the social identity and group conflict theories have been treated as complementary rather than competing and have been combined and jointly referred to as ethnic competition theory. Finally, they mention the theory that focuses on integration policies and attitudes suggesting that different national-level migration and integration policies may mediate between the size of immigrant inflow, economic conditions, and attitudes towards immigration. Their results using data from Rounds 1 through 7 of the European Social Survey challenge predictions of the competitive threat hypothesis and are more consistent with the normative theory of group relations, with its focus on integration policies. Authors show that native members of the societies studied were more likely to experience threat and exhibit anti-immigration attitudes if they were members of vulnerable groups: the unemployed, retired, permanently sick or disabled, women and ageing cohorts. Educated people and students feel less threatened and more open towards immigration in general. The pattern of findings from their model challenges the competitive threat theory and their findings provide an interesting overview of the attitudinal effects of contextual factors. The authors found consistent support for the normative theory of group relations, with its focus on integration policies.

Perception and openness towards migrants are the topic of the third chapter written by Katarzyna Andrejuk. Comparison of ESS data from 2002 and 2014 shows that respondents from many European countries have become less restrictive in their requirements towards potential immigrants. Members of host societies accept more and more multiculturalism and have a growing level of tolerance for different lifestyles. Openness to multiculturalism is also affected by age and the level of education: younger and more educated respondents are more apt to accept immigrants, but the strength of this correlation varies depending on the country. The results also reveal that respondents from the post-communist countries of Central and Eastern Europe are less likely to praise multiculturalism. In their ethnically 
homogeneous states, cultural differences have rarely been part of their everyday experience. However, both in Western Europe and the countries of the post-Soviet bloc, inhabitants manifest similar patterns of acceptance of and preferences for certain groups of migrants.

Chapter five deals with group differences concerning trust in democratic institutions, participation in conventional political protests and cooperation with political parties and associations. Based on data from two rounds of the European Social Survey (ESS, Rounds 6 and 7) Irina Tomescu-Dubrow and Kazimierz M. Slomczynski contrast the political engagement of two groups: people who experience discrimination because of their broadly understood ethnicity and those with xenophobic attitudes, who create an environment that is actually hostile towards 'the others' defined through different ethnicity. The authors find that the impact of belonging to the extreme groups on trust in democratic institutions is relatively strong and negative. In comparison with the majority of society, people who feel discriminated against on grounds of ethnic origin tend to protest more whereas xenophobes are inclined to protest less. Belonging to a group of people discriminated against on grounds of ethnicity has a significant and positive impact on volunteering in civil society organizations.

The second part of the volume deals with legitimization, stratification and health.

In chapter six Andrzej Rychard points out the specificity of trust and legitimization in Poland. Compared to other chapters of the book there is much less empirical analysis in this part (only a table about the dynamic of the index of trust between 2002 and 2014) and the main arguments of the author are mostly theoretical and descriptive. While readers can learn a lot about the political situation in Poland from the democratic transition of the country until the politics of the Tusk government, it is quite surprising to find this chapter in the middle of a book that deals with seven rounds of ESS data.

Henryk Domański, Dariusz Przybysz and Artur Pokropek deal with the question of marital choices in European countries. The authors apply both crossnational and temporal analytical designs to discover differences between countries. As the most important selection criterion is the similarity of the social position between the future husband and wife, the chapter shows changes in time in the association between education and socio-occupational positions of spouses. The increase in international mobility, linked to the expansion of the European Union; the economic and financial crisis of 2008 and the influence of the expansion of higher education in the post-communist countries are three factors considered as reasons for significant changes. According to the results university graduates are much more likely to marry people with a similar status than someone with a lower level of education. This regularity is reflected in the higher likelihood of marriage between the categories at the top of the professional hierarchy while labourers and farmers have fewer such opportunities. These patterns turned out to be very stable. A clear gradation of barriers in marital choices was detected as common to all countries, with senior executives and professionals forming one end of this hierarchy and people with lower social status the other. 
Chapter seven deals with the topic of sleep disorders, an illness that affects a growing number of people. The study of Antonina Ostrowska and Teresa ŻmijewskaJędrzejczyk highlights the social context in which sleep disorders appear. The authors observed the greatest differences over time in Germany and Poland. They found that sleeplessness increases generally with age. Women sleep less well in countries where women and the elderly have relatively lower status. Physical and mental health variables, to a sense of loneliness, and to perception of financial conditions and living conditions in general, also have visible explanatory power according to the findings of the chapter.

The last part of the book contains a chapter devoted to methodological approaches applied in the ESS. The methodological part of the volume is represented by an article written by Paweł B. Sztabiński about the use of mixed mode research design to improve the response rate in face-to-face surveys. The chapter demonstrates results obtained by employing a mixed mode design with the face-to-face mode used alongside self-administered modes. The results of the analyses suggest that the use of the mixed mode in the experiment presented by the article does not lead to surveying additional categories of respondents distinct with respect to the social demographic. Considering that socially isolated people are generally underrepresented in face-toface surveys, this result may suggest that the application of a mixed mode design with a self-administered questionnaire makes it easier to reach such respondents.

Weaknesses of the volume follow from the heterogeneity of its chapters: diversity in terms of the topics that it deals with, but also in terms of the number of countries involved in comparison (from a single country to all countries that took part in the ESS). As New Uncertainties and Anxieties in Europe is an edited volume there is not much that binds the chapters of the volume together beyond the fact that all authors use the data of the European Social Survey.

The volume is a valuable source of inspiration for researchers using ESS data, members of the academic community and students interested in methodological concerns and solutions for challenges of linking theoretical concepts to the variables of the ESS dataset.

DÁNIEL OROSS (arass.danie|⿴囗口苞k.mta.hu) Centre for Sacial Sciences, Hungarian Academy of Sciences 